30. Hunt LW, Gleich GJ, Ohnishi T, Weiler DA, Mansfield ES, Kita H, Sur S Endotoxin contamination causes neutrophilia following pulmonary allergen challenge. Am J Respir Crit Care 1994; 149: 1471-1475.

31. Sandstrom T, Bjermer L, Rylander R. Lipopolysaccharide (LPS) inhalation in healthy subjects increases neutrophils, lymphocytes and fibronectin levels in bronchoalveolar lavage fluid. Eur Respir J 1992; 5: 992-996.

32. Thorn J, Rylander R. Inflammatory response after inhalation of bacteria endotoxin assessed by the induced sputum technique. Thorax $1998 ; 53$ : 1047-1052.

33. Nightingale JA, Rogers DF, Hart LA, Kharitonov SA, Chung KF, Barnes PJ Effect of inhaled endotoxin on induced sputum in normal, atopic, and atopic asthmatic subjects. Thorax 1998; 53: 563-571.

34. Boehlecke BA, Peden D, Hazucha M, Alexis N, Tucker K, Bromberg P. Exposure to low level of endotoxin for four hours increased response to inhaled mite allergen in mild asthmatics [abstract]. Am J Respir Crit Care Med 1999; 159: A699.

35. Michel O, Ginnani R, Duchateau J, Vertongen F, Le Bon B, Sergysels R. Domestic endotoxin exposure and clinical severity of asthma. Clin Exp Allergy 1991; 21: 441-448.

36. Douwes J, Zuidhof A, Doekes G, van der Zee S, Wouters I, Boezen HM, Brunekreef B. (1-3)-B-D-Glucan and endotoxin in house dust and peak flow variability in children. Am J Respir Crit Care Med 2000; 162 : 1348-1354.

37. Sudo N, Sawamura S, Tanaka K, Aiba Y, Kubo C, Koga Y. The requirement of intestinal bacterial flora for the development of an IgE production sytem fully susceptible to oral tolerance induction. J Immunol 1997 ; 159: 1739-1745.

38. Martinez FD. Maturation of immune reponses at the beginning of asthma. J Allergy Clin Immunol 1999; 103: 355-361.

39. Holt PG, Sly PD, Björkstén B. Atopic versus infectious diseases in childhood: a question of balance? Pediatr Allergy Immunol 1997; 8: 53-58.

40. Liu AH, Leung DY. Modulating the early allergic response with endotoxin. Clin Exp Allergy 2000; 30: 1535-1539.

41. Poltorak A, He X, Smirnova I, et al. Defective LPS signaling in C3H/HeJ and $\mathrm{C} 57 \mathrm{BL} / 10 \mathrm{ScCr}$ mice: mutations in Tlr4 gene. Science 1998; 282 2085-2088

42. Arbour NC, Lorenz E, Schutte BC, et al. TLR4 mutations are associated with endotoxin hyporesponsiveness in humans. Nat Genet 2000; 25 : 187-191.

43. M Baldini, IC Lohman, M Halonen, RP Erickson, PG Holt, FD Martinez. A polymorphism in the 5 (flanking region of the CD14 gene is associated with circulating soluble CD14 levels and with total serum Immunoglobulin E. Am J Respir Cell Mol Biol 1999; 20: 976-983.

44. Michel O, Ginanni R, Sergysels R. Protective effect of sodium cromoglycate on lipopolysaccharide-induced bronchial obstruction in asthmatics. Int Arch Allergy Immunol 1995; 108: 298-302.

45. Michel O, Olbrecht J, Moulard D, Sergysels R. Effect of anti-asthmatic drugs on the response to inhaled endotoxin. Ann Allergy Astbma Immunol 2000; 85: 305-310.

\section{Asthma, atopy, antibiotics and the bowel}

\author{
Julian Crane \\ Department of Medicine, School of Medicine, \\ Mein Street, Newtown, Wellington, New \\ Zealand
}

Tel: +64 438559995258

Fax: +64 43895427

E-mail: crane@wnmeds.ac.nz

The past three decades have seen an increase in reported asthma and allergic diseases from many studies around the world, recently described as an epidemic. ${ }^{1}$ While many hypotheses have been developed to explain these changes, the hygiene hypothesis has for the past decade encompassed an expanding link between the epidemiology and immunology of both atopic sensitisation and atopic diseases. These associations and the utility of the hypothesis have recently been reviewed by David Strachan, ${ }^{2}$ who first reported the associations between birth order and hayfever, and articulated the hygiene hypothesis as an explanation. ${ }^{3}$ Inverse relationships between atopic and infectious disease was first raised a decade earlier by Gerrard $e t$ al. in a comparison of atopic disease amongst the Metis (native Indian) and white communities of northern Saskatchewan. ${ }^{4}$ The immunological basis for the hypothesis rests on the concept of immune deviation in early life towards $T$ helper cell (Th) 1 immune responses induced by microbial exposure, with Th1 responses suppressing Th2 responses and immunoglobulin E (IgE) production. The hypothesis therefore refers to IgE-mediated diseases such as hayfever but is less applicable to asthma, where atopy plays an important but not exclusive role.

The relationships between asthma, bronchial hyperresponsiveness (BHR) and atopy have recently been examined among 20- to 44-year-old adults, in five Spanish centres involved in the European Community Respiratory Health Survey. The adjusted proportion of BHR attributable to atopy was $21 \%$ and the proportion of asthma symptoms and BHR attributable to atopy was $42 \% .^{5}$ Factors associated with the hygiene hypothesis such as birth order or specific infections will vary in their strength of association with asthma depending on the proportion of asthma attributable to atopy. An important feature of any useful hypothesis is that it should unify disparate observations. The hygiene hypothesis does this, suggesting explanations for socio-economic variations in atopic disease both within and between countries, and a plausible explanation of some of the long-term upward trends in prevalence. Studies of the relationship between infection or microbial exposures and atopic disease also tend to support the hygiene hypothesis.

The influence of antibiotics on these associations has recently been studied. Farooqi et al. found a twofold risk of doctor-diagnosed atopic diseases with antibiotic treatment in the first 2 years of life, among a general practice birth cohort. $^{6}$ The increased risk was apparent for all classes of antibiotics, although greater for cephalosporins and macrolides; it was independent of the underlying condition being treated, and was similar for those with and without a history of maternal atopy. Antibiotic exposure was the strongest predictor of atopic disease in this study.

The other two studies have examined antibiotic use among children in Sweden and New Zealand, whose families have some association with an anthroposophic lifestyle. Families embracing this lifestyle, whose tenets were set out by Rudolph Steiner in the nineteenth century, tend to minimise their involvement with conventional medical 
practice and therapy, including antibiotics and immunisation. They follow a different educational philosophy for their children, and may alter their diet and sources of food. The Swedish study compared atopy in 5-13 year olds with and without an anthroposophic lifestyle. ${ }^{7}$ Only one-half of the anthroposophic children had ever been exposed to antibiotics, compared with $90 \%$ among the controls. The prevalence of atopy, defined by skin prick testing or Phadiotop-specific IgE, was $24 \%$ in the anthroposophic children compared with $34 \%$ in the controls. The risk of atopy was inversely related to the number of anthroposophic lifestyle characteristics although these could not be individually assessed due to the strong correlations between them. The New Zealand study looked specifically at antibiotic use among 5- to 10-year-old children attending Rudolph Steiner schools in New Zealand in relation to a history of parentally reported atopic disease. ${ }^{8}$ An increased adjusted risk of asthma, wheezing and hayfever was found for any antibiotic use, was stronger for antibiotic use in the first year of life and showed a dose-response relationship with the number of antibiotic courses in the first year of life. This study relied on the parental reporting of atopic disease and did not explore the conditions for which the antibiotics had been prescribed. Reverse causality is clearly possible in this study, although when antibiotics were given in the first year of life but first asthma symptoms occurred after the first year, the risk remained elevated (odds ratio $=7.5,95 \%$ confidence interval $=2.6-22.0$ ) .

While bias and confounding cannot be ruled out as explanations for the associations between antibiotics and atopic sensitisation or disease in these studies, the consistent positive association requires further study. Assuming that the relationship is causal, it could arise either as a direct immunomodulatory effect of antibiotics or through the hygiene hypothesis, either by reducing the effects of specific infections or by altering bowel flora at a time when these bacteria would stimulate Th1 immunity.

Antibiotics have been reported to have direct effects on the immune system, and these reports were recently reviewed by Van Vlem et al. ${ }^{9}$ They concluded that the immunomodulating effects of antibiotics remain heterogeneous, contradictory and, for many drugs, insufficient. Given the strong effects found in the studies previously discussed, investigation of the direct effects of antibiotics on immune development is warranted. Under the hygiene hypothesis, antibiotics could reduce the effects of specific bacterial infection on the developing immune system. This seems unlikely given that, in clinical practice, most antibiotic treatment is empirical without detailed microbiological investigation and often for viral infections.
Attention has focused on the effects of antibiotics on bowel flora, which may be particularly relevant in early life, when the immune system is developing and the bowel is being colonised. Observations in mice suggest that bacterial flora are important for the development of Th1 immunity ${ }^{10}$ and that this can be impaired by antibiotics. ${ }^{11}$ Children in Estonia and Sweden with different patterns of atopic disease have been shown to differ in their bowel flora ${ }^{12}$ and, more recently, atopic children have been shown to be less often colonised by lactobacilli compared with non-atopic children in the same population. ${ }^{13}$ These observations in animal models and in humans require further study both to confirm the findings and to understand the mechanisms. Food prepared with live bacterial culture probably goes back to antiquity in the Middle East and Far East, and for at least 100 years in Europe since Metchnikoff introduced them. Manipulating bowel flora in infancy or in association with antibiotic treatment would be an inexpensive and acceptable intervention that could be readily promoted at a population level.

The role of antibiotics in the acquisition of atopy and atopic disease remains to be proven. There is, however, more than sufficient evidence from animal and human studies to warrant further exploration. Antibiotics may turn out to be an important tributary of the hygiene hypothesis, helping to explain some of the temporal and geographic variation in atopic disorders, and manipulating bowel flora in infancy may provide a route to prevention.

\section{References}

1. Holgate S. The epidemiology of allergy and asthma. Nature 1999; $\mathbf{4 0 2}$ b2-b4.

2. Strachan D. Family size infection and atopy: the first decade of the 'hygiene hypothesis'. Thorax 2000; 55: S2-S10.

3. Strachan DP. Hay fever, hygiene, and household size. Br Med J 1989; 299 1259-1260.

4. Gerrard J, Geddes C, Reggin P, Gerrard C, Horne S. Serum IgE levels in white and Metis communities in Saskatchewan. Ann Allergy 1976; 37: 91-100.

5. Anto JM, Soriano J, Sunyer J. Proportion of asthma attributable to sensitisation to aeroallergens. Eur Resp Rev 1998; 8: 159-160.

6. Farooqi I, Hopkin J. Early childhood infection and atopic disorder Thorax 1998; 53: 927-932

7. Alm J, Swartz J, Lilja G, Schneyius A, Pershagen G. Atopy in children of families with an anthroposophic lifestyle. Lancet 1999; 353 1485-1488.

8. Wickens K, Pearce N, Crane J, Beasley R. Antibiotic use in early childhood and the development of asthma. Clin Exp Allergy 1999; 29 $766-771$

9. Van Vlem B, Vanholder R, De Paepe P, Vogelaers D, Ringoir S. Immunomodulating effects of antibiotics: literature review. Infection 1996; 24: 275-291

10. MacDonald T, Carter P. Requirements for a bacterial flora before mice generate cells capable of mediating delayed hypersensitivity to sheeep red blood cells. J Immunol 1979; 122: 2624-2629.

11. Pulverer G, Ko H, Beuth J. Immunomodulating effects of antibiotics influencing digestive flora. Pathol Biol Paris 1993; 41: 753-758.

12. Sepp E, Julge K, Vasar M, Naaber P, Bjorksten B, Mikelsaar M. Intestinal microflora of Estonian and Swedish infants. Acta Paediatrica 1997; 86 956-961.

13. Bjorksten B, Naaber P, Sepp E, Mikelsaar M. The intestinal microflora in allergic Estonian and Swedish 2-year-old children. Clin Exp Allergy 2000 29: 342-346. 


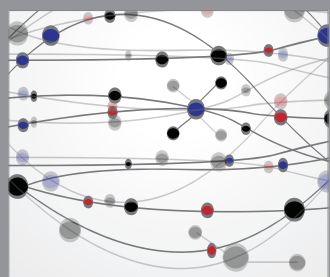

The Scientific World Journal
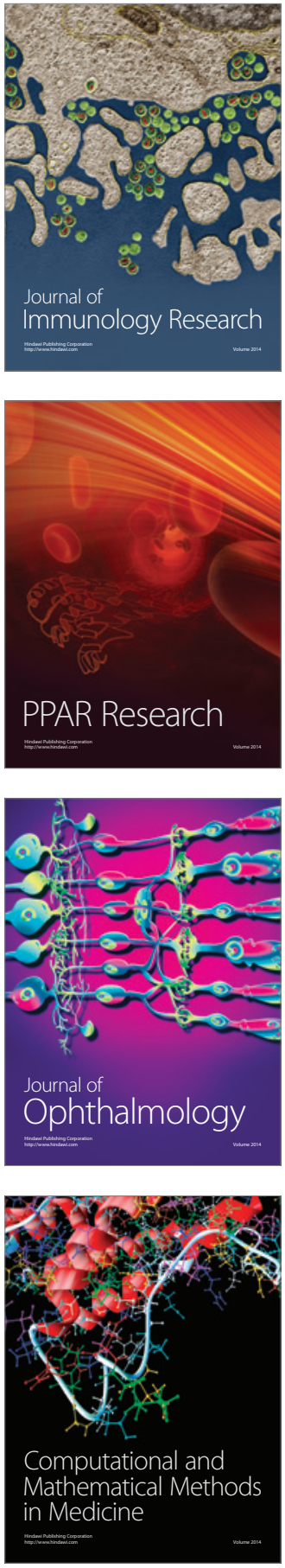

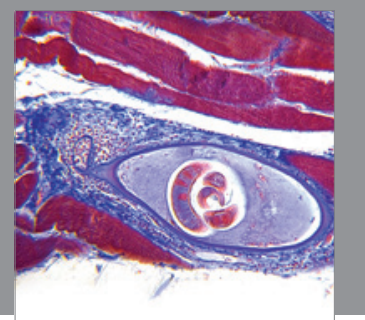

Gastroenterology

Research and Practice
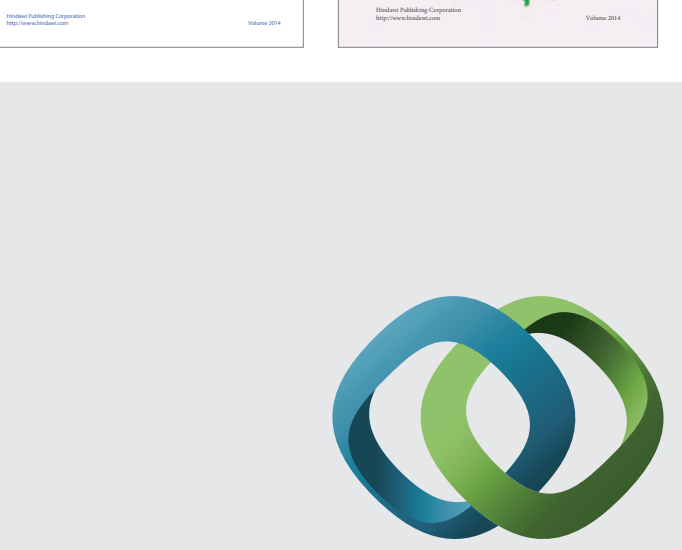

\section{Hindawi}

Submit your manuscripts at

http://www.hindawi.com
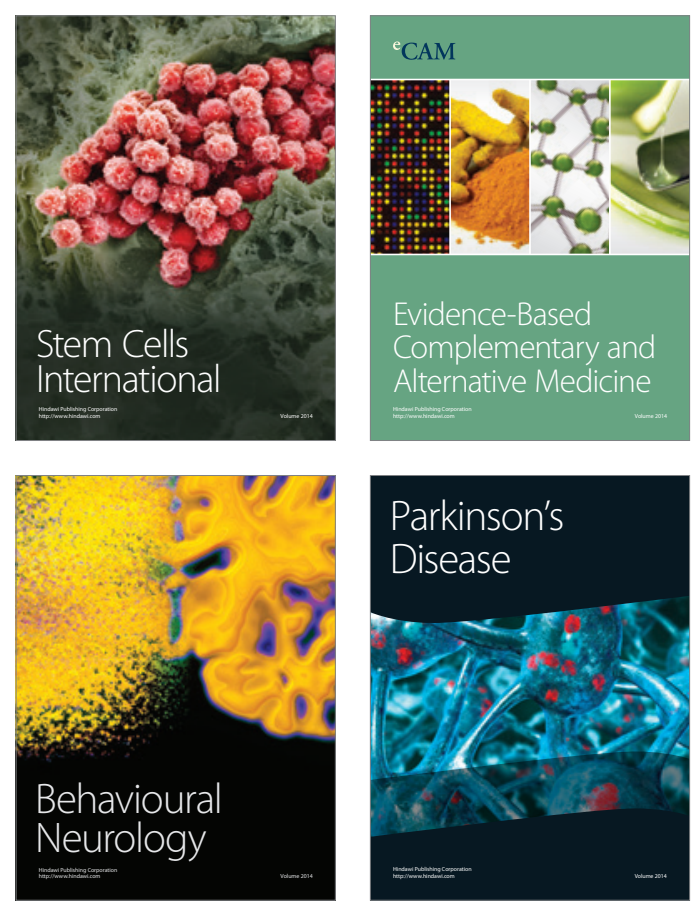

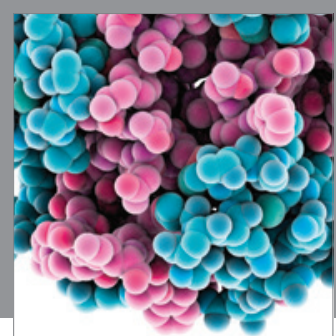

Journal of
Diabetes Research

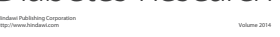

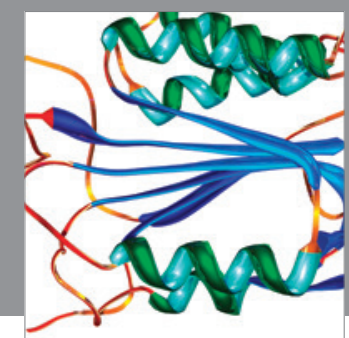

Disease Markers
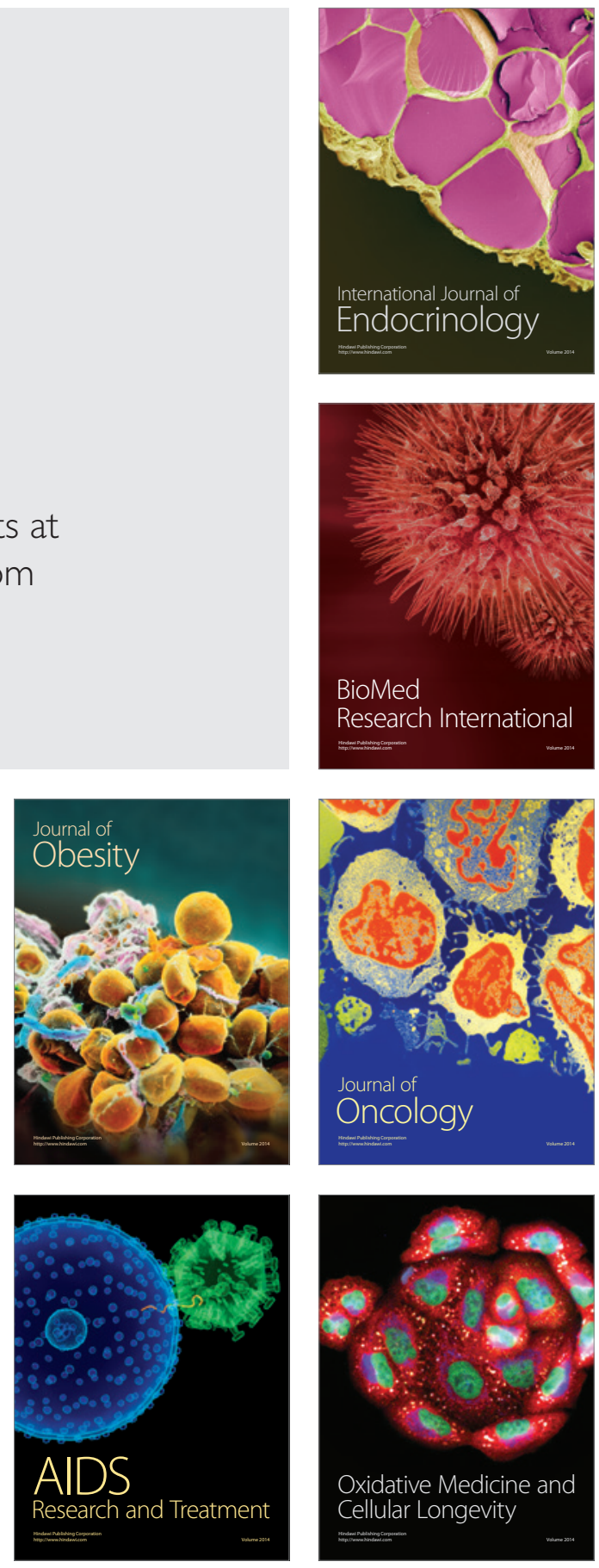